\title{
Substituted Naphthalene-sulfonic Acids ${ }^{1,2}$
}

\author{
I-A Method for Identifying H-Acid and Its Intermediates Obtained from Naphthalene-2,7- \\ disulfonic Acid
}

By D. F. J. Lynch

Col,or Investigation laboratory, Bureat of Chemistry, Washington, D, C.

$A$ method is here proposed for detecting 1,8-dinitro-3,6-naphthalenedisulfonic, 1,8-diamino-3,6-naphthalenedisulfonic, 1,8-aminonaphthol-3,6-disulfonic (H-acid), and 1,8-dihydroxy-naphthalene3,6-disulfonic (chromotropic) acids, which occur in the nitration of naphthalene, 2,7-disulfonic acid and the subsequent reduction and hydrolysis of the dinitro acid.

$\mathrm{T}$

HE POSSIBILITY of detecting and identifying $\mathrm{H}$-acid and its intermediates by means of their insoluble organic salts was suggested by Ambler's ${ }^{3}$ work on the naphthalenesulfonic acids. In the work here reported a large number of organic salts were prepared, but only the more insoluble ones were further studied. The method of making the salts was the same in each case. Molecular equivalent quantities of an inorganio salt of the acid and the hydrochloride of the organic base were dissolved separately in water at room temperature, the two solutions mixed, stirred thoroughly, and allowed to stand for about one-half hour. The crystallized salts were filtered, washed with cold water, and dried in the air.

All the salts were analyzed for water of crystallization in the following manner: From 2 to $3 \mathrm{~g}$. of each salt, after being dried in the air, were allowed to stand in a large closed compartment until a constant weight was reached; then the salt was dried at $100^{\circ} \mathrm{C}$. over sulfuric acid in a vacuum oven; the weighing bottle containing the salt was closed, put in a desiccator, allowed to cool, and weighed.

The sulfur in these salts was determined by ignition with sodium peroxide, as described by Ambler. ${ }^{4}$

\section{ANALYSIS OF SALTS}

BENZIDINE SALT OF 1,8-DINITRO-NAPHTHALENE-3,6-DISULFONIC AcID $\left(\mathrm{C}_{10} \mathrm{H}_{4}\left(\mathrm{NO}_{2}\right)_{2}\left(\mathrm{SO}_{3} \mathrm{H}\right)_{2} \cdot \mathrm{NH}_{2} \mathrm{C}_{6} \mathrm{H}_{4} \cdot \mathrm{C}_{6} \mathrm{H}_{4} \mathrm{NH}_{2}\right)$-This salt separates out in light yellow prisms. At $20^{\circ} \mathrm{C}$., 0.036 part of this salt dissolves in 100 parts of water to give a colorless solution. It is almost equally insoluble in hot water. It contains no water of crystallization and melts with decomposition at $275^{\circ} \mathrm{C}$.

Sulfur found, 11.58 per cent, 11.25 per cent Calculated, 11.39 per cent

CYMIDINE-1,8-DINITRO-NAPHTHALENE-3,6-DISULFONATE $\left(\mathrm{C}_{10} \mathrm{H}_{4-}\right.$ $\left(\mathrm{NO}_{2}\right)_{2}\left(\mathrm{SO}_{3} \mathrm{H}\right)_{2}$. $\left.\left[\mathrm{NH}_{2} \mathrm{C}_{6} \mathrm{H}_{3}\left(\mathrm{CH}_{3}\right) \mathrm{CH}\left(\mathrm{CH}_{3}\right)_{2}\right]_{2}\right)$-This salt separates out in straw-colored prisms. It is soluble in water at room temperature to the extent of 0.059 part in 100 parts of water. It is soluble in hot water, contains no water of crystallization, and melts with decomposition at $265^{\circ} \mathrm{C}$.

Sulfur found, 9.53 per cent, 9.64 per cent

Calculated, 9.47 per cent

Benzidine SalT OF Chromotropic AcId $\left(\mathrm{C}_{10} \mathrm{H}_{3}(\mathrm{OH})_{2}\left(\mathrm{SO}_{3} \mathrm{H}\right)_{2 .-}\right.$ $\mathrm{NH}_{2} \mathrm{C}_{6} \mathrm{H}_{4} \mathrm{C}_{6} \mathrm{H}_{4} \mathrm{NH}_{2}$ ) -This salt separates out in brown prisms. It is soluble at room temperature in water to the extent of 0.085 part per 100 parts of water. It is nearly as insoluble in hot water, contains no water of crystallization, and melts with decomposition at $278^{\circ} \mathrm{C}$.

1 Received December 2, 1921.

2 Contribution No. 57 from the Color Laboratory, U. S. Bureau of Chemistry, Washington, D. C. Published with permission of the Department of Agticulture.

"Naphthaleze Sulfonic Acids. II-A Method for the Qualitative Detection of Some of the Naphthalene Sulfonic Acids," by J. A. Ambler and E. T. Wherry, Thrs Journal, 12 (1920), 1085.

- This Journal, 12 (1920), 1081.
Sulfur found, 12.89 per cent, 12.81 per cent

Calculated, 12.70 per cent

$p$ - NITROTOLUIDINE - 1,8 - DIAMINO - NAPHTHALENE - 3,6 DISULFONATE $\left(\mathrm{C}_{10} \mathrm{H}_{4}\left(\mathrm{NH}_{2}\right)_{2}\left(\mathrm{SO}_{3} \mathrm{H}\right)_{2}\right.$. $\left.\left[\mathrm{NH}_{2} \mathrm{C}_{6} \mathrm{H}_{3}\left(\mathrm{NO}_{2}\right) \mathrm{CH}_{3}\right]_{2}\right)$-This salt separates out in grayish tan needles. It is soluble in water at room temperature to the extent of 0.186 part per 100 parts of water. It is soluble in hot water, contains no water of crystallization, and melts with decomposition at $270^{\circ} \mathrm{C}$.

Sulfur found, 10.15 per cent, 10.35 per cent Calculated, 10.29 per cent

$m$ - $\alpha$-NAPHTHYLAMINE SALT OF H-ACID $\left(\mathrm{C}_{10} \mathrm{H}_{4}\left(\mathrm{NH}_{2}\right)(\mathrm{OH})\right.$ $\left.\left(\mathrm{SO}_{3} \mathrm{H}\right)_{2} . \mathrm{NHIC}_{10} \mathrm{H}_{7}\right)$ - This salt separates out in light violet-gray prisms, is soluble in water at room temperature to the extent of 0.1006 part per 100 parts of water and nearly as insoluble in hot water, contains no water of crystallization, and melts with decomposition at $278^{\circ} \mathrm{C}$.

Stlfur found, 13.67 per cent, 13.71 per cent Calculated, 13.85 per cent

$m$-PsEUdOCUMIDINE SALT OF H-Acrd $\left(\mathrm{C}_{10} \mathrm{H}_{4}\left(\mathrm{NH}_{2}\right)(\mathrm{OH})-\right.$ $\left.\left(\mathrm{SO}_{3} \mathrm{H}\right)_{2} \cdot \mathrm{NH}_{2} \mathrm{C}_{6} \mathrm{H}_{2}\left(\mathrm{CH}_{3}\right)_{3}\right)$-This salt separates out in gray prisms. It is soluble in water at room temperature to the extent of 0.097 part per 100 parts of water, is nearly as insoluble in hot water, contains no water of crystallization, and melts with decomposition at $272^{\circ} \mathrm{C}$.

Sulfur found, 13.93 per cent, 13.98 per cent

Calculated, 14.10 per cent

$m, p$-NITROTOLUIDINE SALT OF $\mathrm{H}$-ACID $\left(\mathrm{C}_{10} \mathrm{H}_{4}\left(\mathrm{NH}_{2}\right)(\mathrm{OH})\right.$ $\left.\left(\mathrm{SO}_{3} \mathrm{H}\right)_{2} \cdot \mathrm{NH}_{2} \mathrm{C}_{6} \mathrm{H}_{3}\left(\mathrm{NO}_{2}\right)\left(\mathrm{CH}_{3}\right) \cdot \mathrm{H}_{2} \mathrm{O}\right)$-This salt separates out in gray prisms. It is soluble in water at room temperature to the extent of 0.106 part per 100 parts of water, is soluble in hot water, contains 1 molecule of water of crystallization, and melts with decomposition at $265^{\circ} \mathrm{C}$.
Sulfur found, 13.40 per cent, 13.51 per cent
Calculated, 13.59 per cent
Water found, 3.62 per cent, 3.58 per cent
Calculated, 3.68 per cent

Tolidine SALTOF H-ACID $\left(\mathrm{C}_{10} \mathrm{H}_{4}\left(\mathrm{NH}_{2}\right)(\mathrm{OH})\left(\mathrm{SO}_{3} \mathrm{H}\right)_{2}, \mathrm{NH}_{2} \mathrm{C}_{6} \mathrm{H}_{3}-\right.$ $\left.\left(\mathrm{CH}_{3}\right)\left(\mathrm{C}_{6} \mathrm{H}_{3}\right) \mathrm{NH}_{2} .3 \mathrm{H}_{2} \mathrm{O}\right)$-This salt separates out in gray-violet prisms. It is soluble in water at room temperature to the extent of 0.102 part per 100 parts of water, is nearly as insoluble in hot water, contains 3 molecules of water of crystallization, and melts with decomposition at $260^{\circ} \mathrm{C}$.

Sulfur found, 11.95 per cent, 11.87 per cent
Calculated, 12.05 per cent
Water found, 9.17 per cent, 9.12 per cent
Calculated, 9.23 per cent

Zinc Salt of 1,8-Diamino-3,6-disulfonic Acid $\left(\mathrm{C}_{10} \mathrm{H}_{4^{-}}\right.$ $\left.\left(\mathrm{NH}_{2}\right)_{2} \mathrm{~S}_{2} \mathrm{O}_{6} \mathrm{Zn} .3 \mathrm{H}_{2} \mathrm{O}\right)$-Upon standing for about one-half hour this salt separates out in gray microscopic needles. It is soluble in hot water and contains 3 molecules of water of crystallization. The zinc was determined according to the method of Huppert and Van Ritter." A weighed amount of dried salt was placed in a porcelain crucible over which was poured cold concentrated nitric acid. The whole was carefully heated until a dry residue remained, then ignited until the residue while hot was pure white. This salt dissolves to the extent of 6.4 parts per 100 parts of water at $20^{\circ} \mathrm{C}$. The excess of zinc sulfate reagent has a salting-out effect.

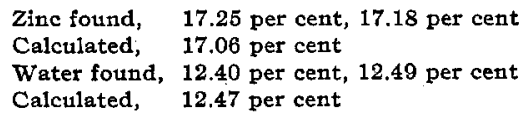

Z. anal. Chem., 35 (1896), 311. 
IDENTIFICATION OF H-ACID AND INTERMEDIATES

(Tests are to be made in 5 to 10 per cent hydrochloric acid solutions, except those with cobalt chloride and zine sulfate, which are made in neutral solutions)

\begin{tabular}{|c|c|c|c|c|c|c|c|c|}
\hline & Benzidine- $\mathrm{HCl}$ & $\begin{array}{c}\text { 2-Cymidine- } \\
\mathrm{H}_{2} \mathrm{HO}_{c} \\
\left(\mathrm{CH}_{3}=1\right)\end{array}$ & $\begin{array}{l}\alpha \text {-Naphthyl- } \\
\text { amine-HCl }\end{array}$ & $\begin{array}{l}\text { Pseudocumi- } \\
\text { dine-HCl }\end{array}$ & Tolidine- $\mathrm{HCl}$ & $\begin{array}{c}p \text {-Nitrotolu- } \\
\text { idine-HCl } \\
(1-2-4)\end{array}$ & $\mathrm{CoCl}_{2}$ & $\mathrm{ZnSO}_{4}$ \\
\hline $\begin{array}{l}1,8 \text { - Di - No2- } \\
3,6 \text {-disulfonic } \\
\text { acid of naph- } \\
\text { thalene }\end{array}$ & $\begin{array}{l}\text { Immediate ppt. } \\
\text { Light straw- } \\
\text { yellow. Wait } \\
5 \text { min. }\end{array}$ & $\begin{array}{l}\text { I m mediate } \\
\text { light straw. } \\
\text { yellow ppt. } \\
\text { Wait } 10 \text { min. }\end{array}$ & No ppt. & No ppt. & No ppt. & No ppt. & No ppt. & No ppt. \\
\hline $\begin{array}{l}1,8-\mathrm{D}_{2}-\mathrm{NH}_{2-} \\
3,6 \text {-disulfonic } \\
\text { acid of naph- } \\
\text { thalene }\end{array}$ & No ppt. & No ppt. & No ppt. & No ppt. & No ppt. & $\begin{array}{l}\text { Gray-tan ppt. } \\
\text { Iet st a nd } \\
15 \text { min. }\end{array}$ & $\begin{array}{l}\text { Brown ppt. } \\
\text { Let stand } 1 / 2 \\
\text { hr. }\end{array}$ & $\begin{array}{l}\text { Ppt. brown. } \\
\text { Let stand } 1 / 2 \\
\text { hr. }\end{array}$ \\
\hline 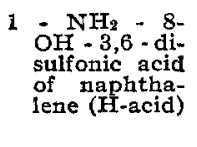 & $\begin{array}{l}\text { A p p t i s } \\
\text { form ed on } \\
\text { long stand- } \\
\text { ing from a } \\
\text { conc. solu- } \\
\text { tion }\end{array}$ & No ppt. & $\begin{array}{l}\text { Ppt. } 1 \text { i g h t } \\
\text { violet - gray. } \\
\text { Let stand } 15 \\
\text { min. }\end{array}$ & $\begin{array}{l}\text { Ppt. tan-gray. } \\
\text { Let stand } 10 \\
\text { min. }\end{array}$ & $\begin{array}{l}\text { P p t. g r a y- } \\
\text { violet. } \\
\text { stand } 10 \text { min. }\end{array}$ & $\begin{array}{l}\text { Ppt. gray. Let } \\
\text { stand } 10 \text { min. }\end{array}$ & No ppt. & No ppt. \\
\hline $\begin{array}{l}1,8-\mathrm{Di}-\mathrm{OH}- \\
3,6 \text {-disulfonic } \\
\text { acid of naph- } \\
\text { thalene } \\
\text { (chromo- } \\
\text { trope acid) }\end{array}$ & $\begin{array}{c}\text { Im m e di a te } \\
\text { brown ppt. } \\
\text { Wait } 10 \text { min. }\end{array}$ & No ppt. & No ppt. & No ppt. & No ppt. & No ppt. & No ppt. & No ppt. \\
\hline
\end{tabular}

Cobalt Salt of 1,8-Diamino-3,6-Disulfonic Acid $\left(\mathrm{C}_{10} \mathrm{H}_{4}\right.$ $\left.\left(\mathrm{NH}_{2}\right)_{2} \mathrm{~S}_{2} \mathrm{O}_{6} \mathrm{Co} .2 \mathrm{H}_{2} \mathrm{O}\right)$-Upon standing for one-half hour this salt separates out in brown microscopic needles. It is soluble in hot water and contains 2 molecules of water of crystallization. The cobalt was determined by heating the cobalt salt slowly and carefully and then igniting the residue of cobalt oxide. This salt dissolves at $20^{\circ} \mathrm{C}$. to the extent of 6 parts per 100 parts of water. Here again the excess of the molar solution of cobalt chloride has a salting-out effect on the salt.

$$
\begin{aligned}
& \text { Cobalt found, } 15.31 \text { per cent, } 15.37 \text { per cent } \\
& \text { Calculated, } 15.51 \text { per cent } \\
& \text { Water found, } 8.71 \text { per cent, } 8.68 \text { per cent } \\
& \text { Calculated, } \quad 8.80 \text { per cent }
\end{aligned}
$$

\section{Method OF IDENTIFICATION}

All the tests may be made in test tubes with 3 to $5 \mathrm{cc}$. of dilute solutions-for example, of concentration less than tenth molar. The organic reagents should be prepared upon the same day as needed by dissolving the organic base in a 10 per cent solution of hydrochloric acid. The zine and cobalt reagents used are molar solutions of the salts of these metals. Before making any of the following tests, however, all sulfates should be removed with barium chloride in the following manner: Bring the solution to boiling and then add an excess of barium chloride solution; allow the solution to stand on the water bath until the precipitate has settled, then filter and wash; bring the filtrate to boiling and add sodium carbonate solution to remove the barium. Neutralize the filtrate with hydrochloric acid. Of the four acids studied only two, $\mathrm{H}$ - and chromotrope acids, form barium salts insoluble in the cold. Both of these salts are soluble in hot water. On cooling, therefore, a precipitate indicates $\mathrm{H}$ - or chromotrope acid.

1,8-Diamino-3,6-Disul Fonic ACID-First test for 1,8-diamino3,6-distulfonic acid, as identification of this acid should be made in a neutral solution, by adding a molar solution of cobalt chloride or zinc sulfate. After standing for one-half hour, the formation of a precipitate indicates the presence of this acid. The precipitate is compact and slow in forming. The presence of the other three acids, however, does not interfere with this precipitation. If, later on, no $\mathrm{H}$-acid is found, 1,8-diamino-3,6-disulfonic acid can be quickly identified and confirmed with the reagent $p$-nitrotoluidine $(1,2,4)$ hydrochloride. This reagent gives an immediate grayish tan precipitate with the diamino acid.

The tests for the other three acids are made in acid solution. Add enough hydrochloric acid to make the resulting mixture a 5 per cent acid solution and let stand one-half hour. If the solution so treated is a concentrated solution of H-acid, its acid sodium salt will be precipitated. Filter out this acid salt. The amount of $\mathbf{H}$-acid left in solution can be easily detected with any of the reagents given in the table and the resulting dilute solution of $\mathrm{H}$-acid will not interfere with the tests for the other acids.

1,8-Dinitro-3,6-DISULFONIC ACID-As seen from the table, cymidine hydrochloride will precipitate only this acid from any mixture of acids of this group. This test should be made before the removal of H-acid, when such removal is necessary, as this acid, like many other nitro compounds, decomposes upon heating. If, however, no chromotrope or $\mathrm{H}$-acid is found afterwards, benzidine hydrochloride will serve as a reagent in confirming the presence of the dinitro acid. There is no difficulty in distinguishing the benzidine salt of the dinitro acid from the one formed with chromotropic acid. These two acids almost never occur in the same working mixture. With such a mixture, however, all the dinitro acid should be removed with a large excess of cymidine hydrochloride. Filter out the dinitro salt and neutralize the filtrate with sodium hydroxide. Filter the free base and evaporate the filtrate down to the original volume before testing for chromotropic acid.

1,8-AMINONAPHTHOL-3,6-DISULFONIC ACID (H-ACID)-This acid is identified by the formation of an insoluble salt with $\alpha$ naphthylamine, tolidine or pseudocumidine hydrochloride in a 5 to 10 per cent acid solution. These reagents do not form insoluble salts with the other three acids. $p$-Nitrotoluidine hydrochloride also forms an insoluble sait with $\mathrm{H}$-acid in an acid solution which will serve for identifying the acid if no diamino acid is present.

Definite positive tests have been obtained in the Color Laboratory with $2 \mathrm{cc}$. of $0.01 M$ solution of $\mathrm{H}$-acid upon the addition of $2 \mathrm{cc}$. of $0.1 \mathrm{M}$ solution of tolidine hydrochloride or $p$-nitrotoluidine hydrochloride. The results of these tests show that by this method it is possible to detect as small amounts as 0.3 per cent of $\mathrm{H}$-acid in a 5 per cent solution of hydrochloric acid. $p$-Nitro$o$-toluidine hydrochloride and pseudocumidine hydrochloride are better reagents because the salts formed are flocculent. In dilute solution the precipitates form more slowly and at least onehalf hour should be allowed for the tests.

Before testing for chromotropic acid remove the $\mathrm{H}$-acid present in the following manner: Add an excess of $p$-nitrotoluidine reagent and allow solution to stand one-half hour for complete precipitation. Filter, and neutralize with sodium hydroxide solution. Filter out the free base and evaporate the solution to its original volume. The solution can then be tested for chromotropic acid.

1,8-DIHYDROXY-3,6-DISULFONIC ACID-If $\mathrm{H}$-acid was present and removed with $p$-nitrotoluidine hydrochloride, test again with that reagent to make sure of the complete removal of $\mathrm{H}$ acid, after which identify chromotropic acid with benzidine hydrochloride.

Experiments with Florida clay deposits, made possible by the coöperation of various Florida cities, are now being conducted at Cornell University to determine whether these clays can be used for the manufacture of brick, tile, and pottery. Clays suitable for filler are also being tested. 